\title{
Inflammasome Up-Regulation and Activation in Dysferlin-Deficient Skeletal Muscle
}

\author{
Rashmi Rawat, Tatiana V. Cohen, Beryl Ampong, \\ Dwight Francia, Andrea Henriques-Pons, \\ Eric P. Hoffman, and Kanneboyina Nagaraju \\ From the Research Center for Genetic Medicine, Children's \\ National Medical Center, and the Department of Integrative \\ Systems Biology, George Washington University School of \\ Medicine and Health Science, Washington, DC
}

A deficiency of the dysferlin protein results in limb girdle muscular dystrophy type $2 B$ and Miyoshi myopathy, with resulting plasma membrane abnormalities in myofibers. Many patients show muscle inflammation, but the molecular mechanisms that initiate and perpetuate this inflammation are not well understood. We previously showed abnormal activation of macrophages and hypothesized that activation of the inflammasome pathway may play a role in disease progression. To test this, we studied the inflammasome molecular platform in dysferlin-deficient human and mouse muscle. Consistent with our model, components of the NACHT, LRR and PYD-containing proteins (NALP)-3 inflammasome pathway were specifically up-regulated and activated in dysferlin-deficient but not in dystrophin-deficient and normal muscle. We demonstrate for the first time that normal primary skeletal muscle cells are capable of secreting IL-1 $\beta$ in response to combined treatment with lipopolysaccharide and the $\mathbf{P} 2 \times 7$ receptor agonist, benzylated ATP, suggesting that not only immune cells but also muscle cells can actively participate in inflammasome formation. In addition, we show that dysferlin-deficient primary muscle cells express tolllike receptors (TLRs; TLR-2 and TLR-4) and can efficiently produce IL-1 $\beta$ in response to lipopolysaccharide and benzylated ATP. These data indicate that skeletal muscle is an active contributor of $\mathrm{IL}-1 \beta$ and strategies that interfere with this pathway may be therapeutically useful for patients with limb girdle muscular dystrophy type 2B. (Am J Pathol 2010, 176:2891-2900; DOI: 10.2353/ajpath.2010.090058)

Genetic defects in the dysferlin gene result in limb girdle muscular dystrophy (LGMD2B) and distal muscular dystro- phy of the Miyoshi type in human patients. ${ }^{1,2}$ The clinical presentation and progression of patients with LGMD2B/ Miyoshi show enigmatic histological and clinical features that are not entirely explained by the myofiber defect. ${ }^{3,4}$ Patients are quite healthy until their late teens. Although there are presymptomatic elevations of serum creatine kinase, there is little evidence of weakness before disease onset, which can appear more acute than that of other dystrophies. The exact nature of the trigger and the molecular pathways that initiate and perpetuate muscle fiber damage and dysfunction in LGMD2B are still unclear.

We and others have previously shown that muscle inflammation is often present in LGMD2B patient biopsies, ${ }^{5-7}$ and dysferlin-deficient monocytes show increased phagocytic activity when compared with control cells. ${ }^{7}$ In addition, we found that smallinterfering RNA-mediated inhibition of dysferlin expression in the $\mathbf{J 7 7 4}$ macrophage cell line resulted in significantly enhanced phagocytosis. Importantly, this experiment demonstrated that the phagocytotic defect seen in both human and murine monocytes is likely a direct consequence of dysferlin deficiency, rather than a downstream effect on monocyte activation in vivo in the dystrophic organism. Dysferlin-deficient mice also showed strong upregulation of the endocytic proteins cation-independent

Supported by the National Institutes of Health (RO1-AR050478 and 5U54HD053177 to K.N.), the Foundation to Eradicate Dystrophy (to K.N.), the US Department of Defense (W81XWH-05-1-0616 to K.N.), and the Jain Foundation (to K.N.). E.P.H.'s research is supported in part by grant M01-RR020359, 5U54HD053177, from the National Institutes of Health, Department of Health and Human Services; the Crystal Ball (Richmond, Virginia), Muscular Dystrophy Association USA; and the US Department of Defense (W81XWH-05-1-0616)

R.R. and T.V.C. contributed equally to this work.

Accepted for publication February 1, 2010

CME Disclosure: None of the authors disclosed any relevant financial relationships.

Supplemental material for this article can be found on http://ajp. amjpathol.org.

Current address of R.R: Office of Biotechnology Products/OPS/CDER. Food and Drug Administration, Bethesda, MD.

Address reprint requests to Kanneboyina Nagaraju, Ph.D., D.V.M., Director, Murine Drug Testing Facility, Research Center for Genetic Medicine, Associate Professor of Pediatrics, the George Washington University Medical Center, Children's National Medical Center, 111 Michigan Avenue NW, Washington, DC 20010. E-mail: knagaraju@cnmcresearch.org. 
mannose 6-phosphate receptor (CIMPR), clathrin, and adaptin- $\alpha$, and LGMD2B muscle exhibited a decreased expression of decay accelerating factor that was not dysferlin-specific. We further showed that the expression levels of the small Rho family GTPases, RhoA, Rac1, and Cdc 42 were increased in the immune cells of dysferlin-deficient mice when compared with control cells, indicating that plasma membrane reorganization and remodeling are active in dysferlin deficiency. ${ }^{7}$ Dysferlin plays a role in vesicle traffic and membrane repair, ${ }^{8,9}$ and recent data from our group have also indicated that dysferlin-deficient muscle, but not Fukutin-related protein- or dystrophin-deficient muscle, shows increased levels of vesicle trafficking pathway proteins (eg, synaptotagmin-like protein, SIp2a and the small GTPase, Rab27A), suggesting that dysferlin-deficient cells may release excess amounts of vesicle contents and contribute to the inflammation and muscle fiber damage associated with this genetic defect. ${ }^{10}$ These data strongly suggest that mild myofiber damage in dysferlin-deficient muscle stimulates an inflammatory cascade (eg, inflammasome) that may initiate, exacerbate, and possibly perpetuate the underlying myofiber-specific dystrophic process. ${ }^{7}$ However, the events that initiate this inflammatory cascade are not yet well characterized.

The molecular platform that triggers the activation of inflammatory caspases and processing of pro-interleukin (IL)- $1 \beta$ to mature (active) IL-1 $\beta$ is termed the inflammasome. ${ }^{11}$ The inflammasome is a multimeric protein complex composed of the NACHT, LRR and PYD-containing proteins (NALP)-3 protein, the apotosis-associated specklike protein containing a caspase recruitment domain (ASC-1), caspase-1, and pro-IL-1 $\beta$. The inflammasome pathway has been well characterized in the cells that participate in innate immunity: $;^{11}$ however, there is very little information regarding its expression and activation in nonhematopoietic cells such as skeletal muscle.

Pro-IL-1 $\beta$ and pro-caspase- 1 are stored in secretory lysosomes, where they await an exocytosis-inducing stimulus; in the absence of such a stimulus, these molecules may undergo lysosomal degradation. ${ }^{12}$ Lysosome exocytosis and IL-1 $\beta$ secretion are facilitated by extracellular ATP. There is evidence that ATP triggers via P2X7 receptors an efflux of $\mathrm{K}^{+}$from the cell, followed by a $\mathrm{Ca}^{2+}$ influx and the activation of phosphatidylcholine-specific phospholipase $\mathrm{C}$ and $\mathrm{Ca}^{2+}$-independent and -dependent phospholipase $\mathrm{A}_{2}$, leading to the secretion of IL-1 $\beta .^{12}$ Recent data further support the concept that inflammasome activation (caspase-1 and IL-1 $\beta$ activation) and the unconventional protein secretion of leaderless proteins such as IL- $1 \beta$ and fibroblast growth factor 2 are interdependent. ${ }^{13}$

The present study is based on the hypothesis that an increase in vesicular trafficking and plasma membrane repair defects result in the release of ATP and other endogenous danger/alarm signals (eg, the high mobility group box 1 [HMGB1] and S100 proteins) in dysferlindeficient muscle. These, in turn, bind to their cellular receptors and activate the inflammasome pathway. We now present evidence that inflammasome components are indeed present in muscle and are activated in dysferlin-deficient patients and mice. Hence, the endogenous danger signals generated as a result of the primary genetic defect in LGMD2B may contribute to the activation of the muscle inflammasome, which in turn generates a proinflammatory environment in muscle that leads to increased muscle inflammation and damage.

\section{Materials and Methods}

\section{Dysferlin-Deficient (LGMD2B, Miyoshi Myopathy) Human Subjects}

Flash-frozen diagnostic muscle biopsies were received by the Research Center for Genetic Medicine at Children's National Medical Center as part of an ongoing for gratis molecular diagnostics program. Biopsies from five dysferlin-deficient subjects (patient 1: female, age at biopsy 19 years; patient 2: female, age at biopsy unknown; patient 3: female, age at biopsy 31 years; patient 4: male, age at biopsy 27 years; and patient 5 : female, age at biopsy 27 years) and five dystrophin-deficient subjects, together with four nondystrophic normal controls were used for the studies described here. Biopsies were characterized for dystrophin and dysferlin by Western blotting (duplicate blots); immunostaining for merosin (laminin- $\alpha$ 2), dystrophin, and $\alpha$ sarcoglycan; and histology (hematoxylin and eosin staining). Biopsies showing a loss of dysferlin by Western blotting ( $0 \%$ to $10 \%$ of normal control levels) but a normal dystrophin Western blot and normal $\alpha$-sarcoglycan and merosin immunostaining were assigned a tentative diagnosis of primary dysferlin deficiency (LGMD2B, Miyoshi myopathy; data not shown). The molecular and clinical features of the dysferlin-deficient patients from whom muscle biopsies were taken have been described previously.

\section{Mice}

All mice were handled according to local Institutional Animal Care and Use Committee guidelines. Dysferlin-deficient SJL/J (JAX number 000686), A/J (JAX number 000646), MDX (JAX number 001801), and C57BI/6J (BL6, JAX number 000664) mice were purchased from Jackson Laboratory (Bar Harbor, ME). The generation and characterization of acid maltase-deficient mice $\left(\mathrm{GAA}^{-/-}\right)$have been described previously. ${ }^{14}$ All mice were housed in an individually vented cage system with a 12-hour light-dark cycle and received standard mouse chow and water ad libitum. Animals were euthanized by using carbon dioxide, and muscle tissue samples were flash-frozen in liquid nitrogen for Western blotting or embedded in OCT compound and frozen in isopentane chilled in liquid nitrogen for immunofluorescent staining.

\section{Isolation of Primary Myoblasts}

Primary myoblasts were isolated from the quadriceps muscle of 8- to 10-day-old SJL/J, MDX, and C57BI/6J mice: muscle tissue was cut into pieces of $<1 \mathrm{~mm}$ and subjected to enzymatic digestion in an enzyme mix containing collagenase/dispase (Roche, Indianapolis, IN) and trypsin (Invitrogen, Carlsbad, CA) in a $37^{\circ} \mathrm{C}$ water bath. The tissue 
was dissociated by repeated pipetting during the incubation, and undigested muscle tissue was allowed to settle by gravity. Supernatants were collected in ice-cold Dulbecco's modified Eagle's medium (DMEM; Invitrogen) containing $10 \%$ fetal bovine serum (FBS; Hyclone, Logan, UT) at each dissociation step. This process was repeated at least two times with fresh enzyme mix. The cell suspension was passed through a 40- $\mu \mathrm{m}$ strainer to remove any remaining clumps and centrifuged at $1500 \mathrm{rpm}$ for 10 minutes. The cell pellet was resuspended in growth medium containing Ham's F-10 (Invitrogen), 20\% FBS, 0.5\% chick embryo extract (Accurate Chemical and Scientific Corp, Westbury, NY), 1\% penicillin-streptomycin (Invitrogen), and $2 \mathrm{mmol} / \mathrm{L}$ L-glutamine (Invitrogen). The cells were then plated on noncoated tissue culture dishes for 1 hour in a $37^{\circ} \mathrm{C} / 5 \% \mathrm{CO}_{2}$ incubator to remove fibroblasts; this plating process was repeated at least twice. Finally, the cells were transferred from the tissue culture dishes to collagen I-coated plates (BD Biocoat, San Jose, CA) and grown in Ham's growth medium for 10 days in a $37^{\circ} \mathrm{C} / 5 \% \mathrm{CO}_{2}$ incubator before subculture for in vitro inflammasome activation experiments. Primary myoblasts were differentiated by replacing the serum with $2 \%$ horse serum after 7 days of culture for an additional 2 days.

\section{Western Blot Analysis}

Human and mouse muscle tissue homogenates were prepared in 1\% NP40 lysis buffer (20 mmol/L Tris-Cl, pH 7.4, with $150 \mathrm{mmol} / \mathrm{L} \mathrm{NaCl}, 1 \mathrm{mmol} / \mathrm{L}$ EDTA, and $1 \% \mathrm{NP} 40$ ) with protease inhibitors. Electrophoresis of proteins was performed on $4 \%$ to $12 \%$ Bis-Tris polyacrylamide gel electrophoresis gels (Invitrogen). Western blotting was performed with antibodies recognizing the P2X7 receptor (Alomone Lab, Israel; 1:500 dilution), NALP-3 (Alexis Biochem, San Diego, CA; 1:1000 dilution), ASC-1 (Alexis Biochem;1:1000 dilution), caspase-1 (Imgenex, San Diego, CA; 1:1000 dilution), IL-1 $\beta$ (a gift from the National Cancer Institute Biometrics Research Branch (NCIBRB) Preclinical Repository, $\mathrm{NCl}$, Fredrick, MD; 1:10,000 dilution), dysferlin (Novocastra Newcastle on Tyne, UK; 1:500 dilution), and Vinculin (SigmaAldrich, St. Louis, MO; 1:2500 dilution) and developed by using Enhanced Chemiluminescence (ECL) (GE Health care, Piscataway, NJ). The autoradiograms were scanned by using an Arcus II scanner (Agfa, Mortsel, Belgium), and volume analysis was performed by using Quantity One software (Bio-Rad Series, Hercules, CA).

\section{IL-1 $\beta$ Secretion and Measurement}

Primary myoblasts or myotubes from C57BL/6J and SJL/J mice were plated at $5 \times 10^{5} \mathrm{cells} / \mathrm{ml}$ in 24-well plates. The next day, the cells were treated with $1 \mu \mathrm{g} / \mathrm{ml}$ lipopolysaccharide (LPS) for 4 hours, followed by the P2X7 receptor agonist benzylated ATP (BzATP; Sigma-Aldrich) at 500 $\mu \mathrm{mol} / \mathrm{L}$ for 30 minutes. Supernatants were collected at the end of the incubation, and IL-1 $\beta$ in the supernatant was measured by enzyme-linked immunosorbent assay (ELISA) by using an IL-1 $\beta$ sandwich ELISA kit (R\&D Systems, Minneapolis, MN) according to the manufacturer's instructions.
The cells were then lysed in 1X lithium dodecyl sulfate (LDS) buffer (Invitrogen), and western blotting was performed by using antibodies detecting IL-1 $\beta$, ASC-1, P2X7, or vinculin.

\section{Immunofluorescent Staining}

Frozen muscle tissue sections from LGMD2B patients and controls were fixed in acetone and blocked with 50\% goat and 50\% human serum. The sections were then incubated with primary antibody for 1 hour at room temperature and detected with Cy3- or fluorescein isothiocyanate-conjugated secondary antibody (Jackson Immunoresearch Laboratory, Inc, West Grove, PA). The slides were then stained with 4',6-diamidino-2-phenylindole (DAPI) and mounted by using Prolong antifade medium (Molecular Probes, Carlsbad, CA). Primary myotubes were fixed in $4 \%$ paraformaldehyde, incubated with primary antibody against P2X7 overnight then detected with Alexa-488 conjugated secondary antibody (Molecular Probes), counterstained with DAPI, and imaged on a Zeiss Aviovert inverted microscope (Zeiss, Thornwood, NY).

\section{Short Hairpin RNA Knockdown}

Freshly prepared primary muscle cells were transiently transfected by using Amaxa Nucleofector kit $\mathrm{V}$ (Lonza, Walkersville, MD) according to the manufacturer's instructions with short hairpin RNA (shRNA) plasmids (SABiosciences, Frederick, MD), containing sequences either specific for dysferlin, 5'-CCTCTACTGTCCACCTATTGT-3', or nonspecific "scrambled" control, 5'-GGAATCTCATTCGATGCATAC-3'. Cultures were incubated in growth media for up to 6 days with media changes after 3 days. Parallel cultures were positively selected for transfected cells by using Geneticin (Invitrogen; $1 \mathrm{mg} / \mathrm{ml}$ ). RAW 264.7 cells (Sigma-Aldrich) were grown in DMEM containing 10\% FBS and antibiotics and transfected as described above.

\section{Flow Cytometry for Toll-Like Receptors}

Myoblast cells, obtained as described above, were detached from culture dishes by using PBS/10 mmol/EDTA (Sigma-Aldrich) for 10 minutes at $4^{\circ} \mathrm{C}$ and then washed two times (1200 $\times g$ for 10 minutes) with ice-cold Dulbecco's phosphate-buffered saline (D-PBS) (Gibco/Invitrogen, Carlsbad, CA). All samples were then frozen in FBS (Gibco/Invitrogen)/10\% dimethyl sulfoxide (SigmaAldrich) and kept at $-80^{\circ} \mathrm{C}$ until use. To label the samples, the cells were washed two times with D-PBS and Fc $\gamma$ receptors were blocked by using DMEM/10\% FBS/ $10 \%$ normal sheep serum (Millipore, Tamecula, CA) for 20 minutes on ice. We next incubated the cells with Alexa 647-conjugated anti-mouse toll-like receptor-2 (TLR-2; Ingenex, San Diego, CA) and phycoerythrin-conjugated anti-TLR-4 (Abcam, Cambridge, MA) for 20 minutes on ice and washed two times with DMEM/10\% FBS. For intracellular MyoD labeling, the cells were incubated for 10 minutes with Perm Solution 2 (BD Biosciences, San Jose, CA), washed two times with D-PBS/0.5\% bovine serum albumin, as recommended by the supplier, and 
then incubated with rabbit anti-mouse MyoD (Santa Cruz, Santa Cruz, CA) for 20 minutes at room temperature. The samples were again washed two times with D-PBS/0.5\% bovine serum albumin and acquired by using a FACSCalibur flow cytometer (BD Biosciences). Data analysis was performed by using CellQuest software version 3.2 (BD Biosciences).

\section{Results}

Components of the Inflammasome Assembly Are Present in Human Skeletal Muscle and Are Up-Regulated in Dysferlin-Deficient Human Muscle

To query the inflammasome pathway in dysferlin deficiency, we examined muscle biopsies of control, LGMD2B (dysferlin deficient), and Duchenne muscular dystrophy (DMD; dystrophin deficient) patients for the presence of protein components of the inflammasome complex. We found an increased expression of NALP-3 in the LGMD2B biopsies when compared with the control and DMD biopsies (Figure 1A). We also observed that pro-caspase-1 expression varied significantly in the control muscle samples, whereas three of the four LGMD2B patients' biopsies and one of the four DMD biopsies showed increased expression of this molecule. Quantitation of pro-caspase- 1 expression showed no significant differences between the control and patients with the disease (LGMD2B and DMD; Figure 1C). ASC-1 expression was increased in both LGMD2B and DMD biopsies when compared with control biopsies (Figure 1, B and C). To localize the expression of caspase- 1 and ASC-1 proteins to specific cell types within the biopsy specimens, we performed immunofluorescent staining of the patients' and control biopsies. ASC-1 expression was clearly increased in the subsarcolemmal region of skeletal muscle, in the blood vessels, and in the infiltrating immune cells of the LGMD2B and dystrophin-deficient muscle (Figure $1 \mathrm{D}$, top middle, top right) when compared with control muscle (Figure 1D, top left). In contrast, caspase-1 expression appeared to be restricted to the infiltrating mononuclear cells, some muscle fibers, and the area around the myonuclei of the muscle fibers in LGMD2B (Figure 1D, bottom middle) but not control or dystrophindeficient muscle (Figure 1D, bottom left, bottom right).

\section{Inflammasome Proteins Are Up-Regulated and Activated in the SJL/J Mouse Model of Dysferlin Deficiency}

We investigated the status of the inflammasome adaptor complex in dysferlin-deficient (SJL/J) and dysferlin-sufficient (C57BI/6J) mice (Figure 2). Analysis of muscle homogenates by Western blotting showed significantly increased expression of pro-caspase- 1 and mature (cleaved) caspase-1 in dysferlin-deficient SJL/J muscle when compared with normal C57BI/6J muscle $(P<0.05)$. In con-
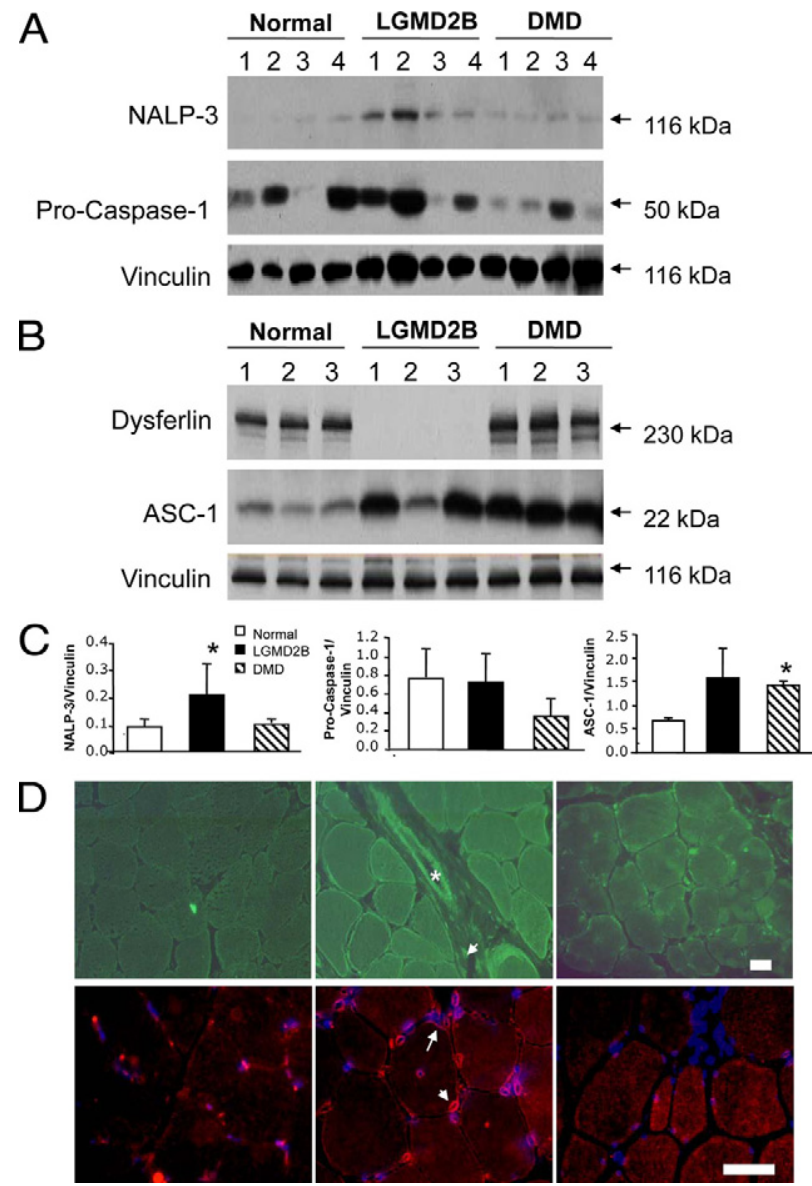

Figure 1. Molecular components of the inflammasome complex are present in human muscle and are up-regulated in LGMD2B muscle biopsies. Muscle tissue lysates were prepared from normal, LGMD2B, and DMD muscle biopsies and analyzed by Western blotting with antibodies recognizing dysferlin, ASC-1, NALP-3, caspase-1, and vinculin. A: NALP-3 (116 kDa) but not pro-caspase-1 $(50 \mathrm{kDa})$ is up-regulated in LGMD2B muscle when compared with DMD and control biopsies. B: Dysferlin $(230 \mathrm{kDa})$ is absent from LGMD2B biopsies, and ASC-1 (22 kDa) expression is increased in LGMD2B and DMD biopsies when compared with controls. Vinculin (116 kDa) was used as a loading control. C: Graphs are quantitation of blot intensity of NALP-3 (left), pro-caspase-1 (middle), and ASC-1 (right) normalized to vinculin. Mean $\pm \mathrm{SD}$ are shown. ${ }^{*} P<0.05$. D: Immunofluorescent staining of LGMD2B and control biopsies shows increased expression of ASC-1 (upper middle) and caspase-1 (lower middle) in LGMD2B muscle when compared with control (left upper and lower) or dystrophin-deficient muscle (right upper and lower), respectively. Arrow denotes up-regulated expression at the fiber membranes; arrowhead denotes up-regulated expression in infiltrating cells. The asterisk marks a blood vessel. Scale bar $=50 \mu \mathrm{m}$.

trast, pro-IL-1 $\beta$ expression was similar in the SJL/J and C57BI/6J muscle samples, and the mature (cleaved) form of $\mathrm{IL}-1 \beta(17 \mathrm{kDa})$ was significantly increased only in dysferlin-deficient and not in control mice (Figure 2, A and B). Similarly, the expression of ASC-1 was increased in dysferlin-deficient as well as dystrophin-deficient muscle when compared with control muscle (Figure 2, A and $B)$, whereas the expression of NALP-3 was specifically increased only in dysferlin-deficient (SJL/J) muscle but not normal (C57BI/6J) and dystrophin-deficient (MDX) muscle (Figure 2, $A$ and $B$ ). These results indicate that molecular components of the NALP-3 inflammasome complex are up-regulated and activated in dysferlin-deficient muscle. To study the disease-specificity of increases in inflammasome markers, we also looked at 
A

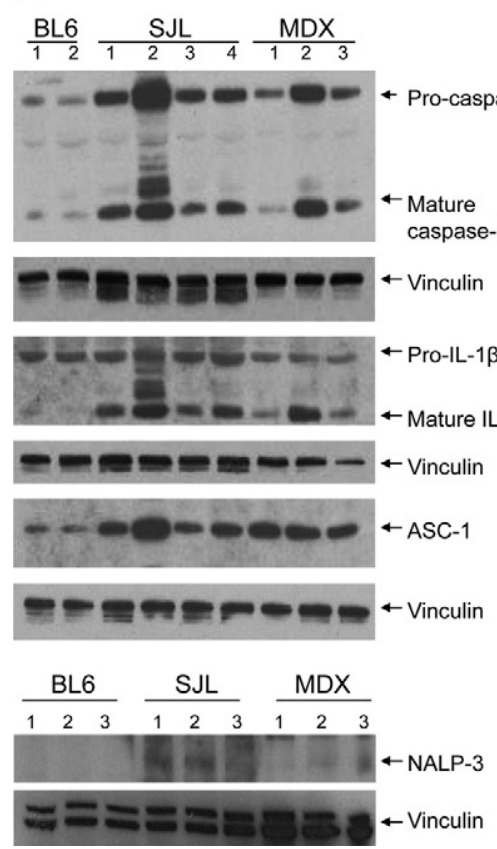

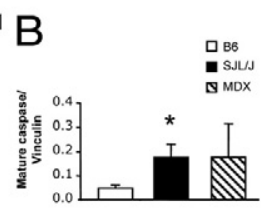
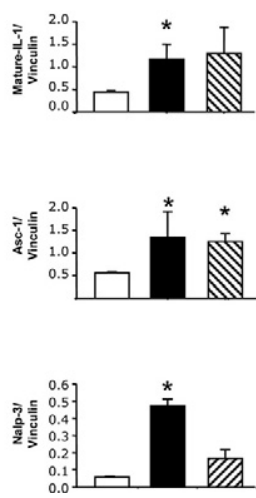

Figure 2. Molecular components of the inflammasome complex are present in a mouse model of dysferlin deficiency ( $\mathrm{SJL} / \mathrm{J}$ mice). A: Muscle lysates from C57BL/6J (BL6), SJL/J, and MDX mice were prepared and analyzed by Western blotting to detect inflammasome components. SJL/J mice showed increased levels of ASC-1 (22 kDa), mature caspase-1 (20 kDa), mature (17 kDa) form of IL-1 $\beta$, and NALP-3 (118 kDa). Vinculin (116 kDa) was used as a loading control. B: Graphs show quantitation of Western blots. C57BL/6J $(n=2) ; \mathrm{SJL} / \mathrm{J}(n=4)$; $\operatorname{MDX}(n=3)$. Mean \pm SD are shown. ${ }^{*} P<0.05$.

another inflammatory myopathic model, MDX, and a noninflammatory myopathic model, the acid maltase-deficient mice (GAA ${ }^{-1-}$; Supplemental Figure S1, see http://ajp. amjpathol.org). ASC-1 expression in both DMD patients and in MDX mouse muscle is clearly increased (Figures 1B and $2 A$ ), whereas as NALP-3 expression is increased only in LGMD2B and SJL/J mouse muscle. In contrast to SJL/J mice, up-regulation of mature caspase- 1 and IL- $1 \beta$ was not statistically significant in MDX mice (Figure 2B), whereas in $\mathrm{GAA}^{-1-}$ mouse muscle, the inflammasome components (ASC-1, IL-1 $\beta$, and caspase-1) were not upregulated (Supplemental Figure S1, see http://ajp.amjpathol.org).

\section{Expression of the ATP Receptor P2X7 Is Increased in the Muscle of SJL/J Mice as Compared with C57BL/6J Control Mice}

Extracellular ATP is known to trigger caspase-1 activation and IL-1 $\beta$ secretion, ${ }^{15}$ and membrane instability in dysferlin-deficiency would be expected to increase ATP release from myofibers. The functional ATP receptor is P2X7 (P2X receptor 7). Analysis of P2X7 expression in dysferlin-deficient mouse muscle by Western blotting showed the receptor to be significantly higher in dysferlin-deficient mice compared with C57BI/6J control mice (Figure 3, A and B). No significant increase in P2X7 was observed in the muscle tissue of acid-maltase $\left(\mathrm{GAA}^{-/-}\right)$deficient mice (Data not shown).
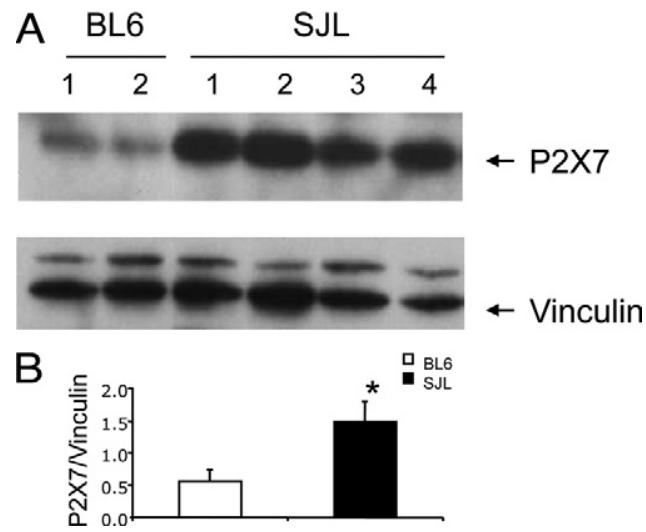

Figure 3. $\mathrm{P} 2 \mathrm{X} 7$ receptor expression is increased in the muscle of $\mathrm{SJL} / \mathrm{J}$ mice when compared with $\mathrm{C} 57 \mathrm{BL} / 6 \mathrm{~J}$ control mice. A: Muscle lysates from SJL/J and $\mathrm{C} 57 \mathrm{BL} / 6 \mathrm{~J}$ mice were examined by Western blotting with $\mathrm{P} 2 \mathrm{X} 7$ receptor antibody. The expression of the $\mathrm{P} 2 \mathrm{X} 7$ receptor $(\sim 68 \mathrm{kDa})$ was higher in SJL/J muscle than in C57BL/6J muscle. B: Quantitation of P2X7R expression in muscle lysates from SJL/J $(n=4)$ and control C57BL/6J mice $(n=2)$. Mean $\pm \mathrm{SD}$ are shown. ${ }^{*} P<0.05$

\section{Lipopolysaccharide and Benzylated ATP Induce IL-1 $\beta$ Synthesis and Secretion in Primary Myoblasts}

We tested the ability of the inflammasome complex to be activated by lipopolysaccharide (LPS) and the P2X7 agonist, BzATP, by using the downstream read-out of IL-1 $\beta$ release from SJL/J and C57BI/6J primary myoblasts. The myoblasts were treated with $1 \mu \mathrm{g} / \mathrm{ml}$ LPS for 4 hours, followed by $500 \mu \mathrm{mol} / \mathrm{L}$ BzATP for 30 minutes. The culture supernatants were collected for the IL-1 $\beta$ ELISA, and cell lysates were prepared for Western blot analysis. $\mathrm{IL}-1 \beta$ is constitutively present at low levels in SJL/J but not C57BL/6J myoblasts (Figure 4A). Even though IL-1 $\beta$ was readily induced upon LPS treatment in both strains, dysferlin-deficient myoblasts showed a significantly higher level of IL-1 $\beta$ expression in response to LPS stimulation (Figure 4A). Treatment with BzATP alone did not affect the level of IL-1 $\beta$ synthesis in either strain. Treatment with both LPS and BzATP resulted in decreased pro-IL-1 $\beta$ expression (Figure 4A) in cell lysates and increased IL-1 $\beta$ secretion into culture supernatants from both strains (Figure 4B). A similar decrease in ASC-1 and P2X7 was also noted in LPS/BzATP-treated cells, indicating that this combination triggered the release of $\mathrm{IL}-1 \beta$ as well as other components of the inflammasome complex into supernatant thus reducing the levels in cell lysates. Both the synthesis and secretion of IL-1 $\beta$ were significantly higher in dysferlin-deficient myoblasts than in control myoblasts (Figure 4, A and B). Analysis of ASC-1 and P2X7 expression showed a significant constitutive increase in dysferlin-deficient but not control primary myoblasts (Figure 4A). To eliminate the possibility of a strainspecific effect, we also performed these studies in myoblasts from another model of dysferlin deficiency, A/J mice, and found similar increase in secretion of $\mathrm{IL}-1 \beta$ on LPS/BzATP stimulation relative to C57BI/6 controls (data not shown). As these primary myoblasts express dysferlin (Supplemental Figure S2B, see http://ajp.amjpathol.org), these data support our hypothesis that the inflammasome pathway is up-regulated and active in myoblasts. 
A

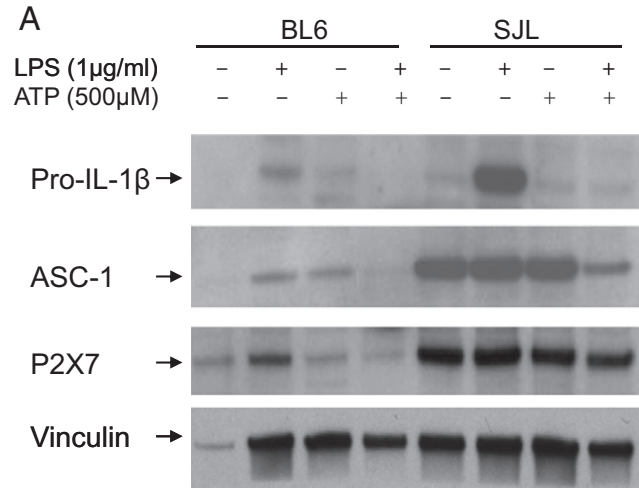

B

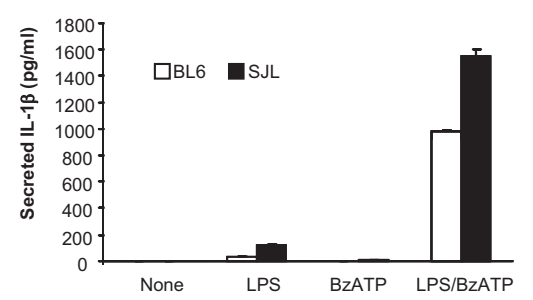

C

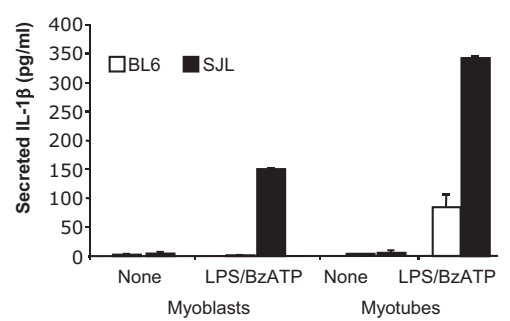

Figure 4. A combination of LPS and BzATP induces enhanced IL- $1 \beta$ secretion in dysferlin-deficient primary myoblasts. Primary myoblasts from SJL/J and $\mathrm{C} 57 \mathrm{BL} / 6 \mathrm{~J}$ mice were stimulated with LPS and BzATP; culture supernatants were collected for IL- $1 \beta$ ELISA, and cell lysates were prepared for Western blot analysis. A: Western blot analysis shows increased induction of pro-IL-1 $\beta$ and constitutive activation of ASC- 1 and P2X7R in lysates of dysferlin-deficient muscle. Note the loss of IL- $1 \beta$ from lysates of myoblasts stimulated with LPS and BzATP. B: ELISA shows the effect of LPS and BzATP on IL- $1 \beta$ secretion from $\mathrm{SJL} / \mathrm{J}$ and $\mathrm{C} 57 \mathrm{Bl} / 6 \mathrm{~J}$ myoblasts: stimulation of myoblasts with LPS alone resulted in IL- $1 \beta$ synthesis, but not secretion from myoblasts. In contrast, stimulation with LPS and BzATP induced increased secretion of IL- $1 \beta$ in dysferlin-deficient primary muscle cells and corresponding loss of pro-IL- $1 \beta$ from the lysates ( $n=3 \pm$ SEM). C: ELISA shows IL- $1 \beta$ secretion in both myoblasts and myotubes in response to LPS and BzATP treatment $(n=3 \pm \mathrm{SEM})$.

\section{Mature Myotubes Express Up-Regulated Inflammasome Pathway Components}

Data from our lab and others suggest that the expression of dysferlin is up-regulated on differentiation in muscle cultures $^{16}$ (Supplemental Figure S2B, see http://ajp. amjpathol.org). Thus, we aimed to test whether the inflammasome pathway would remain up-regulated in muscle cultures after differentiation. We cultured primary muscle cells for 7 days and induced them for 2 days to differentiate and fuse into myotubes. We compared BzATP/LPSstimulated IL-1 $\beta$ secretion in myoblasts and myotubes. We found that both myoblasts and mytubes produce significant levels of IL-1 $\beta$. Dysferlin-deficient SJL/J myoblasts and myotubes produce more IL- $\beta$ than normal muscle cells (Figure 4C). To ensure that the cultures contained mostly myogenic cells and differentiated suffi-
A

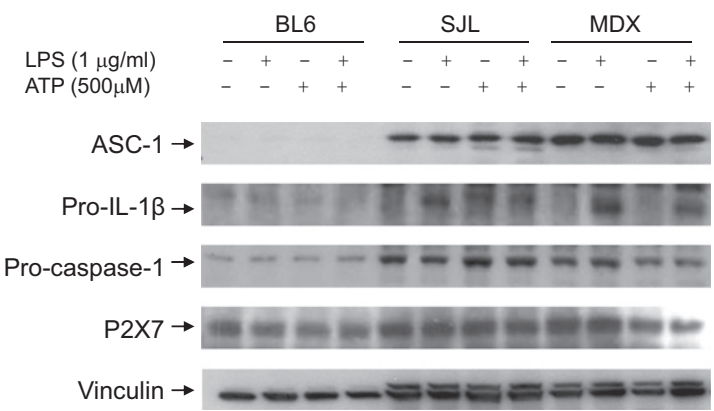

B

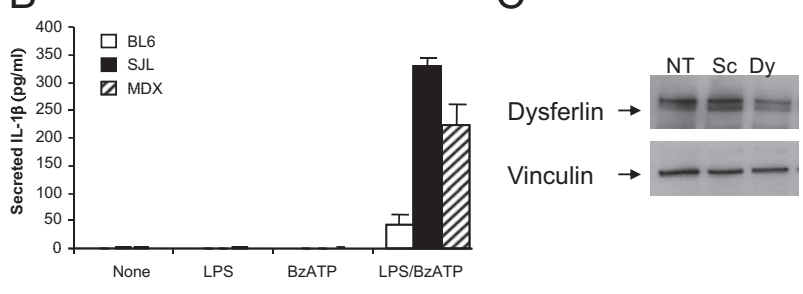

$\mathrm{D}$
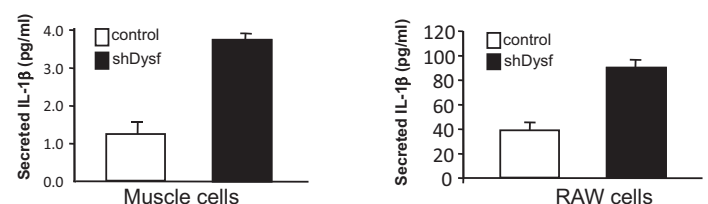

Figure 5. Enhanced IL- $1 \beta$ secretion in dysferlin-deficient primary mature myotubes. Primary $\mathrm{C} 57 \mathrm{Bl} / 6, \mathrm{SJL} / \mathrm{J}$, and MDX muscle cultures were grown for 7 days then differentiated into mature myotubes for 2 days. Myotubes were stimulated with LPS and BzATP, and then supernatants and lysates were analyzed for ELISA and Western blotting. A: Western blot analysis shows increased expression of ASC-1, pro-caspase-1, pro-IL-1 $\beta$, and P2X7 in lysates of dysferlin-deficient muscle. B: ELISA shows the effect of LPS and BzATP on IL- $1 \beta$ secretion from $\mathrm{C} 57 \mathrm{Bl} / 6 \mathrm{~J}, \mathrm{SJL} / \mathrm{J}$, and MDX mature myotubes: stimulation with LPS and BzATP induced increased secretion of IL- $1 \beta$ in dysferlin- and dystrophin-deficient primary myotubes compared with $\mathrm{C} 57 \mathrm{Bl} / 6 \mathrm{~J}$ muscle $(n=3 \pm$ SEM). C: shRNA knockdown of dysferlin increases LPS/BzATPstimulated IL-1 $\beta$ secretion. Western blot shows dysferlin expression from nontransfected (NT) primary muscle cells, or cells transiently transfected with scrambled shRNA (Sc) or dysferlin shRNA (Dy). Vinculin was used as a loading control. D: ELISA shows up-regulated IL- $1 \beta$ secretion in primary muscle cells transiently transfected with dysferlin shRNA compared with controls (left). Up-regulated IL- $1 \beta$ secretion was also observed in RAW cells that were transiently transfected with dysferlin shRNA compared with controls (right).

ciently, we analyzed the cultures for expression of myogenic markers MyoD and desmin by immunofluorescence. After 9 days in vitro, the muscle cultures contained many myotubes that expressed MyoD and desmin. The cultures also expressed P2X7 in myotubes as well as mononuclear myoblast cells in the mixed cultures (Supplemental Figure 2A, see http://ajp.amjpathol.org).

We tested MDX mice as another inflammatory muscle disease control. Myotubes derived from C57BI/6J, SJL/J, and MDX mice were stimulated with LPS, BzATP, or LPS/BzATP, then immunoblotted for caspase- $1, \mathrm{IL}-1 \beta$, P2X7, and ASC-1. Similar to our findings in myoblasts, pro-caspase, P2X7, and ASC-1 were up-regulated in SJL/J myotubes (Figure 5A). We also analyzed myotube culture supernatants by using an ELISA for IL-1 $\beta$. The levels of IL- $1 \beta$ in the untreated mature myotubes were below detection limit of our ELISA assay $(<1 \mathrm{pg} / \mathrm{ml})$. However, stimulation with both LPS and BZATP resulted in up-regulated levels of mature IL- $1 \beta$ in SJL/J (329.5 \pm 
$14.1 \mathrm{pg} / \mathrm{ml} ; n=4)$ and MDX (222.5 \pm 37.4) compared with stimulated C57BL/6J myotubes (42.7 \pm 14.4 ), indicating that dysferlin-deficient myotubes also secrete more IL-1 $\beta$ (Figure 5B). To determine whether the increased IL-1 $\beta$ in SJL/J muscle is due to dysferlin-deficiency, we performed shRNA knockdown of dysferlin in wild-type cells. Transient transfection of shRNA plasmids containing dysferlin resulted in 30\% to 50\% knockdown compared with nontransfected cells or cells transfected with a nonspecific "scrambled" shRNA plasmid, as estimated by Western blot analysis for dysferlin (Figure 5C; Supplemental Figure S2B, see http://ajp.amjpathol.org). Transient transfection of primary muscle cells resulted in a measurable degree of cell death thus reducing the overall level of elicited IL-1 $\beta$ secretion. However, in shRNA-dysferlin transfected muscle cells, IL- $1 \beta$ was upregulated compared with control cells $(3.8 \pm 0.04,1.6 \pm$ 0.22 , respectively; $n=3 ; P=0.04$; Figure $5 \mathrm{D}$ ). Since dysferlin is expressed in macrophages, we also transiently transfected the macrophage cell line RAW264.7 with dysferlin-shRNA and scrambled-shRNA plasmids. Control RAW cells expressed levels of IL- $1 \beta$ that were higher than muscle cells $(40.3 \pm 5.3 \mathrm{pg} / \mathrm{ml})$, and knockdown of dysferlin increased IL- $1 \beta$ by approximately twofold to $89.3 \pm 7.3 \mathrm{pg} / \mathrm{ml}(n=2 ; P=0.03$; Figure $5 \mathrm{D})$ in these cells.

\section{Primary Myoblasts Express TLRs-2 and -4}

The inflammatory process including activation of IL- $1 \beta$ is initiated by the recognition of damage-associated molecular patterns by the TLRs. ${ }^{17}$ To determine whether TLRs are present in the myoblast cultures, we have analyzed the expression of TLR-2 and TLR-4 by flow cytometry. Initially we determined the percentage of muscle precursors in our mixed myoblast cultures by using the myogenic marker MyoD. Our cultures consisted predominantly of MyoD positive cells with $90.8 \%$ in C57BI/6J and $89.5 \%$ in SJL/J cells (Figure 6A). Analysis of MyoD positive cells showed that $74.6 \%$ of the C57BI/6J and $76.3 \%$ of the SJL/J cells were positive for TLR-2 expression (Figure $6 \mathrm{~B}$ ). Our analysis also showed that $21.1 \%$ of the C57BI/6J cells and $25.1 \%$ of the SJL/J cells were positive for TLR-4 expression, suggesting that both TLR-2 and TLR-4 are expressed in primary skeletal muscle cells (Figure 6C).

\section{Discussion}

In the present study, we provide evidence that myogenic cells contain the molecular components necessary to form an inflammasome, that these components can be activated by LPS and BzATP, and that key inflammasome adaptor proteins are up-regulated and activated in dysferlin-deficient skeletal muscle.

The inflammasome pathway has been well characterized in innate immune cells ${ }^{18}$; however, there is very little information on its activation in nonhematopoietic cells such as skeletal muscle. The particular nature of the stimulus has been shown to determine the use of specific
A Solid line - WT / Dashed line - SJL
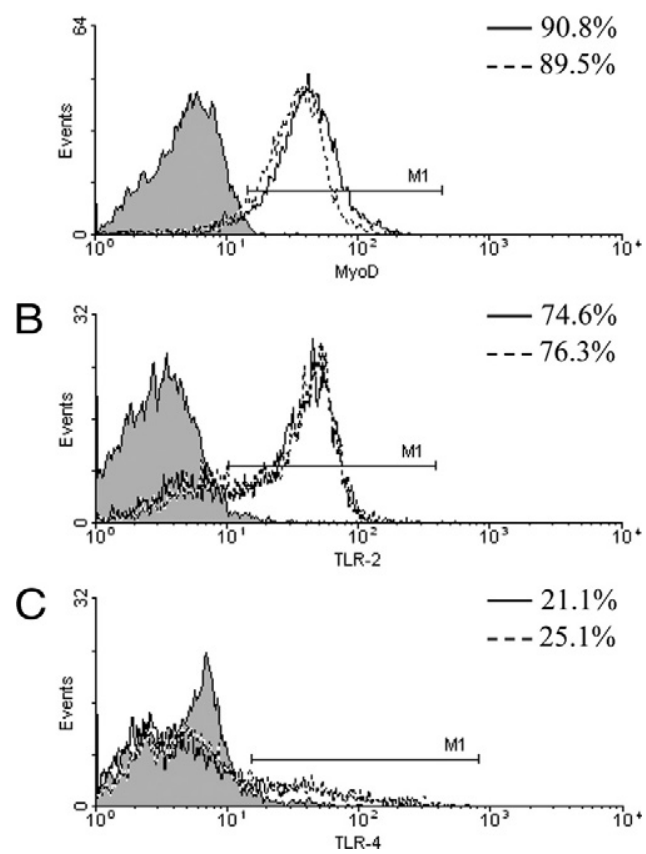

Figure 6. Expression of toll-like receptors in primary myoblasts. Flow cytometry analysis of myoblasts from $\mathrm{C} 57 \mathrm{Bl} / 6 \mathrm{~J}$ (solid line) and $\mathrm{SJL} / \mathrm{J}$ (dotted line) mice. Cultures were derived from three animals of each genotype and pooled for analysis. Gray histograms are isotype control. A: Staining for MyoD shows $90.8 \%$ MyoD positive cells in $\mathrm{C} 57 \mathrm{BL} / 6 \mathrm{~J}$ and $89.5 \%$ MyoD positive cells in SJL/J cultures. B: Staining for TLR-2 shows $74.6 \%$ TLR-2 positive cells in $\mathrm{C} 57 \mathrm{Bl} / 6$ and $76.3 \%$ TLR-2 positive cells in SJL/ 6 cultures. C: Staining for TLR- 4 shows $21.1 \%$ TLR- 4 positive cells in C $57 \mathrm{Bl} / 6$ and $25.1 \%$ TLR-4 positive cells in SJL/ 6 cultures.

adaptor molecules (NALP1, NALP2, NALP3, NALP6, NALP12, and caspase recruitment domain (CARD) inhibitor of NF- $\kappa$ B-activating ligands (CARDINAL) $)^{17,19,20}$ in the inflammasome activation pathway. Myofiber necrosis results in migration of monocytes into the muscle, where they become tissue macrophages. Activated tissue macrophages are a rich source of inflammatory cytokines, toxic radicals, and inflammatory lipid mediators. These products are capable of causing extensive tissue damage to the host, and there is considerable data suggesting that dystrophin-deficient myofibers are more vulnerable to damage from these mediators than is normal muscle. ${ }^{21,22}$ Signals from damaged or stressed cells may initiate an immune response even in the absence of infection, the so-called "danger model" of the immune response. ${ }^{23}$ Such signals may be generated when cells undergo necrosis, which initiates inflammation and immune responses; in contrast, physiological apoptotic cell death does not trigger inflammation. ${ }^{23}$ Several natural activators of the inflammasome have recently been identified, such as the uric acid crystals associated with gout, ${ }^{24,25}$ bacterial RNA, ${ }^{26}$ extracellular ATP, and the $\mathrm{Ca}^{2+}$ channel affecting marine toxin maitotoxin. ${ }^{18}$ TLRs are known to sense several of these endogenous ligands and activate the intracellular signaling pathways. ${ }^{27}$ The inflammasome platform of molecular interactions is a part of innate immunity that is receiving increased attention for its role in tissue pathologies. Mammalian hosts have evolved mechanisms to rapidly and efficiently recognize 
not only foreign invaders (microbes) but also damage- or injury-associated self proteins. These proteins are recognized by germline-encoded pattern recognition receptors that provide a first line of defense. Pattern recognition receptors recognize damage-associated molecular patterns, which are either derived from pathogens (pathogen-associated molecular patterns) or are self proteins (stress- or danger-associated molecular patterns). ${ }^{28,29}$ Recognition of damage-associated molecular patterns by TLRs initiates a signaling cascade, leading to the activation of the proinflammatory caspase- 1 . The inflammatory cytokines IL-1 $\beta, I L-18$, and potentially IL-33 are synthesized as precursors that can be processed by caspase- 1 into the bioactive forms, although IL-33 processing is still controversial. ${ }^{17}$ In chronic inflammatory conditions, it is likely that some of the self proteins released from damaged cells act as stress or danger-associated molecular patterns. Strong caspase-1 activation signal, either through pathogen-associated molecular patterns or stress- or danger-associated molecular patterns, is a signature of the inflammasome complex and a mechanism of inducing cell damage as a protective mechanism of innate immunity.

Our data obtained for dysferlin-deficient muscle are consistent with the increasing evidence that endogenous ligands can stimulate TLR pattern recognition receptors and trigger an immune/inflammatory response that involves the activation of nuclear factor $\kappa \mathrm{B}(\mathrm{NF}-\kappa \mathrm{B})$ and generation of interleukins, including IL-1 $\beta$. Signals from damaged or stressed cells may initiate an immune response via TLRs even in the absence of infection, the so-called "danger model" of the immune response. ${ }^{23,30}$ TLRs are involved in the recognition of various microbial-derived molecules, including LPS, lipoteichoic acid, double-stranded RNA and peptidoglycan, as well as unmethylated bacterial DNA. The TLR-mediated intracellular signaling pathways assemble the inflammasome complex as well as activate NF- $к \mathrm{~B}$. Activated NF- $\kappa \mathrm{B}$ induces transcription of a series of cytokine/ chemokine genes including $\mathrm{IL}-1 \beta$, an integral member of the inflammasome complex. ${ }^{27}$ TLR expression is observed in immune cells as well as a variety of other cells, including vascular endothelial cells, adipocytes, cardiac myocytes, and intestinal epithelial cells. ${ }^{31}$ Recent data further indicate that proinflammatory proteins such as HMGB1 interact with both TLR-2 and TLR-4 to initiate the inflammatory process. ${ }^{32}$ These data clearly indicate that TLRs recognize endogenous ligands and probably play a role in chronic conditions such as LGMD2B.

In our study, an analysis of human muscle tissues from normal and mutation-defined LGMD2B and DMD patients also showed an increased expression of two inflammasome components, caspase-1 and ASC-1, in the muscles of both dysferlin (LGMD2B, SJL/J) and dystrophin (DMD, MDX)-deficient tissues when compared with normal controls (normal, C57BI/6J). The NALP-3 protein was found to be increased only in dysferlin-deficient (LGMD2B, $\mathrm{SJL} / \mathrm{J}$ ) muscle tissues. We note that there is some variation in the expression of NALP-3 between patients. This is likely due to heterogeneity of the patient population, age of the patient, duration of disease, and sampling effects. Thus, our data indicate that the activation of the NALP-3 inflammasome is specific to dysferlin deficiency in humans (LGMD2B) and mice (SJL/J). Expression of ASC-1 was also found to be up-regulated in the SJL/J muscle and not in C57BL/6J muscle. ASC-1 plays a central role not only in NALP-3 but also in absent in melanoma-2 (AIM-2) inflammasome pathway. ${ }^{17,33}$ These finding suggest that in dysferlin-deficient muscle, an increase in

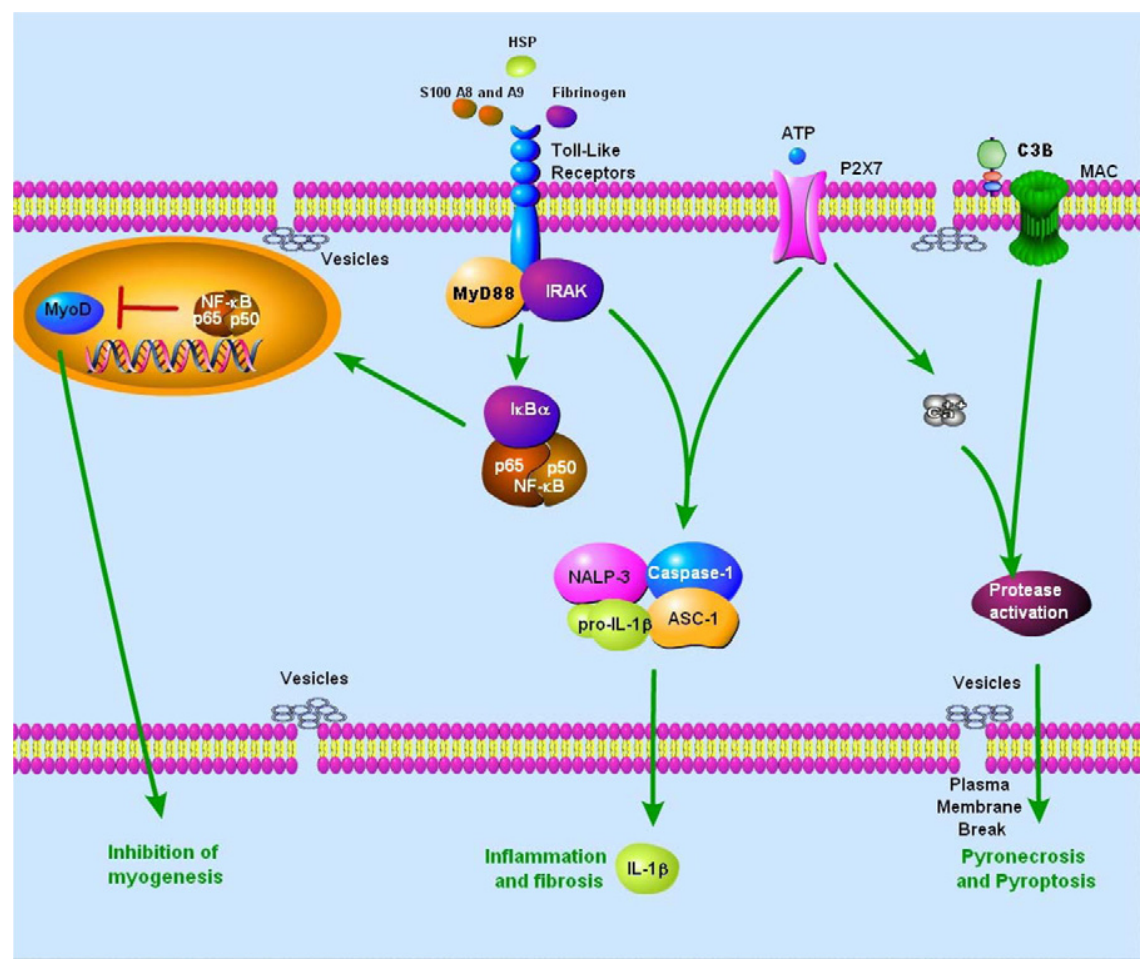

Figure 7. Mechanisms of inflammation and muscle fiber damage in dysferlin deficiency. Factors that initiate and perpetuate the disease are not well understood. It is likely that age-related physiological changes in skeletal muscle in conjunction with environmental insults may initiate the disease process in LGMD2B. Because dysferlin is expressed both in skeletal muscle and macrophages, it is likely that the phenotype is due to abnormalities in both cell types. Here we propose that increase in vesicular trafficking and plasma membrane repair defects results in release in ATP and other endogenous danger/ alarm signals (eg, HMGB1, S100 proteins, etc). These, in turn, bind to their cellular receptors (TRLs, P2X7 receptors) and activate inflammasome (ASC-1, NALP-3, caspase-1, and IL-1 $\beta$ ) and NF- $\kappa$ B pathways. Extracellular ATP and complement components, which are also activated, are known to induce additional pores on plasma membrane resulting in an influx of calcium and activation of calcium-dependent proteases, pyroptosis, and pyronecrosis. Further, activation of NF- $\kappa \mathrm{B}$ in this disease may induce not only muscle fiber wasting but also inhibition of myogenesis. All of these downstream processes activate not only inflammation and fibrosis but significant muscle fiber damage and dysfunction. HSP, heat-shock protein; MAC, membrane attack complex; IRAK, IL-1R-associated kinase. 
NALP-3 inflammasome, can lead to the activation of caspase- 1 and subsequent cleavage and activation of IL-1 $\beta$. To rule out any nonspecific up-regulation of inflammasome proteins in SJL/J muscle, we also examined one inflammatory (MDX) and one noninflammatory muscle disease model, the acid maltase-deficient mouse $\left(\mathrm{GAA}^{-1-}\right)$, and found that ASC-1, pro-IL-1 $\beta$, and pro-caspase-1 were up-regulated in the muscle tissue of SJL/J mice and MDX mice but not $\mathrm{GAA}^{-1-}$ mice, whereas NALP-3 was expressed only in SJL/J but not MDX mice, suggesting NALP-3 inflammasome is active in dysferlin-deficient, but not dystrophin-deficient, muscle. The presence and increased expression of ASC-1, pro-IL-1 $\beta$, and pro-caspase-1, and absence of NALP-3 indicate that NALP-3 independent inflammasome (eg, AIM-2 inflammasome) may be active in dystrophin-deficient human and mouse skeletal muscle. ${ }^{33}$ Even though these studies show that NALP-3 inflammasome is active in dysferlindeficient muscle, we cannot rule out the role for this pathway in other inflammatory muscle disease such as fascioscapulohumeral dystrophy or inflammatory myopathies (Polymyositis and Dermatomyositis).

$\mathrm{IL}-1 \beta$ activation and release require two distinct signals: the first signal can be triggered by TLR activation, which leads to the synthesis of pro-IL- $1 \beta$, and the second signal involves caspase- 1 activation. IL-1 $\beta$ release can be triggered by activation of the surface-expressed purinergic receptors of the P2X7 subtype, for which ATP is the main endogenous ligand. ${ }^{15,34}$ P2X7-deficient mice have been shown to be completely defective in IL-1 $\beta$ secretion. We have now shown that the expression of the P2X7 receptor in dysferlin-deficient SJL/J mice is highly up-regulated when compared with C57BL/6J normal control and GAA ${ }^{-1-}$ myopathic mice. This finding is consistent with evidence that P2X7 receptor expression is increased under inflammatory conditions. ${ }^{35}$ Our data demonstrate that ATP released from dysferlin-deficient cells can trigger P2X7 activation and IL- $1 \beta$ release in dysferlin-deficient patients and mice.

We have further validated these findings in isolated dysferlin-deficient and -sufficient primary mouse muscle. Our attempts to perform these experiments in dysferlindeficient $\mathrm{C} 2 \mathrm{C} 12$ and $\mathrm{H}-2 \mathrm{~K}$ muscle cells were unsuccessful because neither of those cell lines produced detectable levels of IL- $1 \beta$. The exact reasons for not detecting $\mathrm{IL}-1 \beta$ in those cell types are currently unclear. However, secretion of LPS- and BzATP-induced IL-1 $\beta$ was significantly higher in dysferlin-deficient primary myoblasts and myotubes than normal muscle cells (C57BL/6J). The decrease in IL-1 $\beta$ and ASC- 1 expression that we observed on LPS and BzATP stimulation suggests that some of the inflammasome vesicles are secreted and released into the culture supernatant along with IL- $1 \beta$. LPS significantly induced pro-IL-1 $\beta$ synthesis in the dysferlin deficient mice; however, neither LPS nor BzATP alone could enhance the IL-1 $\beta$ secretion, indicating that both signals are needed for efficient secretion of IL- $1 \beta$ from skeletal muscle cells.

Muscle biopsy samples from patients with dysferlin deficiency show numerous extra-structural membrane defects. ${ }^{36}$ Also, in dysferlin-null mice, the membranes of muscle fibers fail to re-seal in the presence of calcium after laser-induced membrane damage, confirming a role for dysferlin in vesicle traffic and membrane repair. ${ }^{8,9}$ Recent data from our group have also indicated that dysferlindeficient muscle, but not Fukutin-related protein- or dystrophin-deficient muscle, shows increased levels of vesicle trafficking pathway proteins (eg, synaptotagmin-like protein, Slp2, and the small GTPase, Rab27A), suggesting that dysferlin-deficient cells may release excess amounts of vesicle contents and contribute to the inflammation and muscle fiber damage associated with this genetic defect. ${ }^{10}$

Based on the data presented in this article and our previous publications, we now propose the following model to account for the pathogenesis associated with dysferlin deficiency, which generally does not become manifest until the late teenage years (Figure 7). The exact factors that initiate and perpetuate the disease are not known; however, it is likely that age-related physiological changes in the skeletal muscle, together with environmental insults, can initiate the disease process in LGMD2B. Because dysferlin is expressed in both skeletal muscle and macrophages, it is likely that the phenotype is due to abnormalities in both cell types. We now propose that the increase in vesicular trafficking and plasma membrane repair defects associated with LGMD2B results in the release of ATP and other endogenous danger/alarm signals (eg, HMGB1 and S100 proteins or unknown proteins). These molecules, in turn, bind to their cellular receptors (TLRs, P2X7 receptors) and activate the inflammasome pathway. Extracellular ATP and complement components, which are also activated, are known to induce additional pores in the plasma membrane, resulting in an influx of $\mathrm{Ca}^{2+}$ and activation of $\mathrm{Ca}^{2+}$-dependent proteases. We suggest that Rab27A/Slp2a expression in LGMD2B muscle provides a compensatory vesicle trafficking pathway that is able to repair the membrane damage in the absence of dysferlin. However, this same compensatory pathway may release excess quantities of vesicle contents, contributing to the cellular damage and inflammatory microenvironment seen in dysferlin deficiency. All these downstream processes activate not only inflammation and fibrosis but also lead to significant muscle fiber damage and dysfunction.

\section{Acknowledgments}

We thank Dr. Nina Raben for providing $\mathrm{GAA}^{-/-}$mouse tissues for inflammasome analysis, and Dr. Paul Plotz for the critical review and comments on this work.

\section{References}

1. Liu J, Aoki M, Illa I, Wu C, Fardeau M, Angelini C, Serrano C, Urtizberea JA, Hentati F, Hamida MB, Bohlega S, Culper EJ, Amato AA, Bossie K, Oeltjen J, Bejaoui K, McKenna-Yasek D, Hosler BA, Schurr E, Arahata K, de Jong PJ, Brown RH Jr: Dysferlin, a novel skeletal muscle gene, is mutated in Miyoshi myopathy and limb girdle muscular dystrophy. Nat Genet 1998, 20:31-36

2. Bashir R, Britton S, Strachan T, Keers S, Vafiadaki E, Lako M, Richard I, Marchand S, Bourg N, Argov Z, Sadeh M, Mahjneh I, Marconi G Passos-Bueno MR, Moreira Ede S, Zatz M, Beckmann JS, Bushby K: A gene related to Caenorhabditis elegans spermatogenesis factor 
fer- 1 is mutated in limb-girdle muscular dystrophy type 2B. Nat Genet 1998, 20:37-42

3. Ho M, Gallardo E, McKenna-Yasek D, De Luna N, Illa I, Brown RH Jr: A novel, blood-based diagnostic assay for limb girdle muscular dystrophy 2B and Miyoshi myopathy. Ann Neurol 2002, 51:129-133

4. Arahata $\mathrm{K}$, Ishii $\mathrm{H}$, Hayashi YK: Congenital muscular dystrophies, Curr Opin Neurol 1995, 8:385-390

5. Gallardo E, Rojas-Garcia R, de Luna N, Pou A, Brown RH Jr, Illa I: Inflammation in dysferlin myopathy: immunohistochemical characterization of 13 patients. Neurology 2001, 57:2136-2138

6. Confalonieri P, Oliva L, Andreetta F, Lorenzoni R, Dassi P, Mariani E, Morandi L, Mora M, Cornelio F, Mantegazza R: Muscle inflammation and $\mathrm{MHC}$ class I up-regulation in muscular dystrophy with lack of dysferlin: an immunopathological study. J Neuroimmunol 2003, $142: 130-136$

7. Nagaraju K, Rawat R, Veszelovszky E, Thapliyal R, Kesari A, Sparks S, Raben N, Plotz P, Hoffman EP: Dysferlin deficiency enhances monocyte phagocytosis: a model for the inflammatory onset of limbgirdle muscular dystrophy 2B. Am J Pathol 2008, 172:774-785

8. Bansal D, Miyake K, Vogel SS, Groh S, Chen CC, Williamson R, McNeil PL, Campbell KP: Defective membrane repair in dysferlindeficient muscular dystrophy. Nature 2003, 423:168-172

9. Lennon NJ, Kho A, Bacskai BJ, Perlmutter SL, Hyman BT, Brown RH $\mathrm{Jr}$ : Dysferlin interacts with annexins $\mathrm{A} 1$ and $\mathrm{A} 2$ and mediates sarcolemmal wound-healing. J Biol Chem 2003, 278:50466-50473

10. Kesari A, Fukuda M, Knoblach S, Bashir R, Nader GA, Rao D, Nagaraju K, Hoffman EP: Dysferlin deficiency shows compensatory induction of Rab27A/Slp2a that may contribute to inflammatory onset. Am J Pathol 2008, 173:1476-1487

11. Martinon F, Tschopp J: Inflammatory caspases: linking an intracellular innate immune system to autoinflammatory diseases. Cell 2004, 117:561-574

12. Andrei C, Dazzi C, Lotti L, Torrisi MR, Chimini G, Rubartelli A: The secretory route of the leaderless protein interleukin 1 beta involves exocytosis of endolysosome-related vesicles. Mol Biol Cell 1999, 10:1463-1475

13. Keller M, Ruegg A, Werner S, Beer HD: Active caspase- 1 is a regulator of unconventional protein secretion. Cell 2008, 132:818-831

14. Raben N, Nagaraju K, Lee E, Kessler P, Byrne B, Lee L, LaMarca M, King C, Ward J, Sauer B. Plotz P: Targeted disruption of the acid alpha-glucosidase gene in mice causes an illness with critical features of both infantile and adult human glycogen storage disease type II. J Biol Chem 1998, 273:19086-19092

15. Ferrari D, Pizzirani C, Adinolfi E, Lemoli RM, Curti A, Idzko M, Panther E, Di Virgilio F: The P2X7 receptor: a key player in IL-1 processing and release. J Immunol 2006, 176:3877-3883

16. De Luna N, Gallardo E, IIla I: In vivo and in vitro dysferlin expression in human muscle satellite cells. J Neuropathol Exp Neurol 2004, 63:1104-1113

17. Martinon F, Burns K, Tschopp J: The inflammasome: a molecular platform triggering activation of inflammatory caspases and processing of prolL-beta. Mol Cell 2002, 10:417-426

18. Mariathasan S, Weiss DS, Newton K, McBride J, O'Rourke K, RooseGirma M, Lee WP, Weinrauch Y, Monack DM, Dixit VM: Cryopyrin activates the inflammasome in response to toxins and ATP. Nature 2006, 440:228-232

19. Agostini L, Martinon F, Burns K, McDermott MF, Hawkins PN,
Tschopp J: NALP3 forms an IL-1beta-processing inflammasome with increased activity in Muckle-Wells autoinflammatory disorder. Immunity 2004, 20:319-325

20. Wang L, Manji GA, Grenier JM, Al-Garawi A, Merriam S, Lora JM, Geddes BJ, Briskin M, DiStefano PS, Bertin J: PYPAF7, a novel PYRIN-containing Apaf1-like protein that regulates activation of NFkappa B and caspase-1-dependent cytokine processing. J Biol Chem 2002, 277:29874-29880

21. Hartigan-O'Connor D, Kirk CJ, Crawford R, Mule JJ, Chamberlain JS Immune evasion by muscle-specific gene expression in dystrophic muscle. Mol Ther 2001, 4:525-533

22. Villalta SA, Nguyen HX, Deng B, Gotoh T, Tidball JG: Shifts in macrophage phenotypes and macrophage competition for arginine metabolism affect the severity of muscle pathology in muscular dystrophy. Hum Mol Genet 2009, 18:482-496

23. Matzinger P: An innate sense of danger. Semin Immunol 1998, 10:399-415

24. Martinon F, Glimcher LH: Gout: new insights into an old disease. J Clin Invest 2006, 116:2073-2075

25. Martinon F, Petrilli V, Mayor A, Tardivel A, Tschopp J: Gout-associated uric acid crystals activate the NALP3 inflammasome. Nature 2006, 440:237-241

26. Kanneganti TD, Ozoren N, Body-Malapel M, Am A, Park JH, Franchi L, Whitfield J, Barchet W, Colonna M, Vandenabeele P, Bertin J, Coyle A, Grant EP, Akira S, Nunez G: Bacterial RNA and small antiviral compounds activate caspase-1 through cryopyrin/Nalp3. Nature 2006, 440:233-236

27. Barton GM, Medzhitov R: Toll-like receptor signaling pathways. Science 2003, 300:1524-1525

28. Seong SY, Matzinger P: Hydrophobicity: an ancient damage-associated molecular pattern that initiates innate immune responses. Nat Rev Immunol 2004, 4:469-478

29. Takeda K, Kaisho T, Akira S: Toll-like receptors. Annu Rev Immunol 2003, 21:335-376

30. Frantz S, Kelly RA, Bourcier T: Role of TLR-2 in the activation of nuclear factor kappaB by oxidative stress in cardiac myocytes. J Biol Chem 2001, 276:5197-5203

31. Zhang FX, Kirschning CJ, Mancinelli R, Xu XP, Jin Y, Faure E, Mantovani A, Rothe M, Muzio M, Arditi M: Bacterial lipopolysaccharide activates nuclear factor-kappaB through interleukin-1 signaling mediators in cultured human dermal endothelial cells and mononuclear phagocytes. J Biol Chem 1999, 274:7611-7614

32. Park JS, Gamboni-Robertson F, He Q, Svetkauskaite D, Kim JY Strassheim D, Sohn JW, Yamada S, Maruyama I, Banerjee A, Ishizaka A, Abraham E: High mobility group box 1 protein interacts with multiple Toll-like receptors. Am J Physiol Cell Physiol 2006, 290:C917-924

33. Fernandes-Alnemri T, Yu JW, Datta P, Wu J, Alnemri ES: AlM2 activates the inflammasome and cell death in response to cytoplasmic DNA. Nature 2009, 458:509-513

34. Burns K, Martinon F, Tschopp J: New insights into the mechanism of IL-1beta maturation. Curr Opin Immunol 2003, 15:26-30

35. Humphreys BD, Dubyak GR: Modulation of P2X7 nucleotide receptor expression by pro- and anti-inflammatory stimuli in THP-1 monocytes. J Leukoc Biol 1998, 64:265-273

36. Selcen D, Stilling G, Engel AG: The earliest pathologic alterations in dysferlinopathy. Neurology 2001, 56:1472-1481 